\title{
Geographic variation in trace-element signatures in the statoliths of near-hatch larvae and recruits of Concholepas concholepas (loco)
}

\author{
Patricio H. Manríquez ${ }^{1,2, *}$, Sylvana P. Galaz ${ }^{2}$, Tania Opitz ${ }^{2}$, Scott Hamilton ${ }^{3}$, \\ George Paradis ${ }^{4}$, Robert R. Warner ${ }^{5}$, Juan Carlos Castilla ${ }^{6}$, Fabio A. Labra ${ }^{7,8}$, \\ Nelson A. Lagos ${ }^{7}$ \\ ${ }^{1}$ Instituto de Ciencias Marinas y Limnológicas, and ${ }^{2}$ Laboratorio Costero de Recursos Acuáticos de Calfuco, \\ Universidad Austral de Chile, Casilla 567, Valdivia, Chile \\ ${ }^{3}$ Moss Landing Marine Laboratories, 8272 Moss Landing Road, Moss Landing, California 95039, USA \\ ${ }^{4}$ Department of Geological Sciences and Marine Science Institute, and ${ }^{5}$ Department of Ecology, Evolution, \\ and Marine Biology, University of California, Santa Barbara, California 93106, USA \\ ${ }^{6}$ Departamento de Ecología and Center for Advanced Studies in Ecology \& Biodiversity, Facultad de Ciencias Biológicas, \\ Pontificia Universidad Católica de Chile, Casilla 114-D, Santiago, Chile \\ ${ }^{7}$ Centro de Investigación en Ciencias Ambientales, Facultad de Ciencias, Universidad Santo Tomás, Ejercito 146, Chile \\ ${ }^{8}$ Instituto de Ecología y Biodiversidad, Casilla 653, Santiago, Chile
}

\begin{abstract}
Spatial variation of trace elements in calcified structures (otoliths, statoliths, and shells) has been used to track the movements of individuals among habitats, and connectivity between marine populations. In the present study, we used laser ablation-inductively coupled plasma mass spectrometry to quantify the concentrations of trace elements in statoliths of prehatch larvae and recruits of the gastropod Concholepas concholepas from 3 regions in Chile. We also examined spatial variation in chemical signatures deposited during larval life and at the time of settlement in intertidal habitats. We found significant differences between 3 geographic regions in the trace element concentrations recorded in natal statoliths of near-hatch larvae and in natal core and edge areas of recruit statoliths. Discriminant function analysis indicates that natal signatures of near-hatch larvae and the cores and edges of recruit statoliths show spatial segregation among regions. High levels of reclassification success of larvae to the origin region suggest potential for assigning recruits to the corresponding matching region. Concentrations of trace elements in the natal cores of recruit statoliths fell relatively close but did not overlap with the discriminant space occupied by larvae, and at regional scales the pattern of geographic variation of recruit statoliths resembles that of larval statoliths. This suggests population grouping and little population interchange at this regional scale. Assessing population stocks and connectivity of this species at smaller scales along the Chilean coast will only be possible with more finely structured sampling and a better understanding of temporal variation in the chemical environment.
\end{abstract}

KEY WORDS: Chilean coast - Statolith microchemistry - Trace element - Larvae · Recruits · LA-ICPMS · Concholepas

\section{INTRODUCTION}

An improved understanding of larval dispersal in marine invertebrates and fishes can have important consequences for the management of marine fish- eries and the design of marine protected areas (Planes et al. 2009, Halpern \& Warner 2003, Thorrold et al. 2007). Larval dispersal distances determine the ability of protected areas to facilitate self-recruitment and determine the scale of spill-over into adjacent 
marine areas (Palumbi 2002). Stock assessment, quantification of larval dispersal, identification of recruitment sources, and contribution of populations from different regions to fishery stocks provide information on major ecological factors with important consequences for management decisions, and all of these factors depend on knowledge of population connectivity.

The hard calcified structures present in many marine organisms, such as fish otoliths or gastropod statoliths, grow by deposition of new layers throughout the life of the organism. Chemical elements present in these hard structures may permanently record information about the chemical composition of the water masses the organisms have passed through during their development. However, the chemical composition of these hard structures can also be influenced by the physical and biological environment such as salinity, temperature, and diet (Zacherl et al. 2003a, Bath-Martin et al. 2004, Zumholz et al. 2006, 2007). Although many studies of elemental composition of otoliths have assessed larval connectivity in fish (Thorrold et al. 2002, Ruttenberg et al. 2005, 2008, Ruttenberg \& Warner 2006, Hand et al. 2008), there is a limited amount of work in marine invertebrates such as gastropods and cephalopods (Zacherl et al. 2003a,b, Doubleday et al. 2008, Warner et al. 2009). Trace element analysis assumes that otoliths and statoliths act as recorders of the environment throughout the lifetime of the individual, from the natal environment to their adult environment. However, this assumption requires the development of a reference collection of natal statoliths of pre-dispersal larval stages (i.e. chemical signature of the natal site) that can be compared with the natal cores of statoliths obtained from recruits. Although several studies have demonstrated the potential uses of trace element signatures in statoliths of benthic invertebrates (e.g. Zacherl et al. 2003b, Warner et al. 2009), this approach has not been applied to the study of populations on a broad geographic scale.

In Chile, the gastropod Concholepas concholepas plays a key ecological role in rocky intertidal and subtidal habitats (Moreno et al. 1984, Castilla \& Durán 1985) and is the main invertebrate species targeted by small-scale fishers (Castilla \& Defeo 2001, Leiva \& Castilla 2002). The sustainability of this natural resource may in part be maintained through the establishment of marine protected areas as sites of rich larval production (Manríquez \& Castilla 2001). However, to be effective, larval production from marine reserves must be successfully exported to fished areas. C. concholepas spends $3 \mathrm{mo}$ in the pelagic environment (DiSalvo 1988), and can delay settlement and metamorphosis in the absence of appropriate benthic cues (Manríquez \& Castilla unpubl. data), so it has the capacity to stay in the pelagic phase for long periods. Genetic evidence suggests it is possible that $C$. concholepas may disperse over distances of several 100s of kilometers (Gallardo \& Carrasco 1996, Kinlan \& Gaines 2003, Cárdenas et al. 2009). There is currently little empirical evidence to allow us to quantify the effectiveness of larval dispersal in this species and the true distances over which it occurs in ecological scale. This information is important for determining the appropriate size, placement, and spacing of marine protected areas and ensuring the capacity of these areas to adequately replenish the overfished stocks of $C$. concholepas.

In the present study we attempted to discriminate regional differences between populations of Concholepas concholepas based on trace element analysis of their statoliths in larval and recruit stages. The advantage of using C. concholepas as a biological model for investigating connectivity is the presence of 3 discrete life stages: (1) a pre-dispersal phase that lasts approximately 2 mo, where embryos develop inside egg capsules attached to the rocks in intertidal and subtidal environments, ending with the hatching of veliger larvae (Gallardo 1973); (2) a 3 mo pelagic dispersal phase culminating in settlement and metamorphosis, as advective processes and larval behavior potentially influence the return of larvae to shore (Poulin et al. 2002, Manríquez \& Castilla 2011); and (3) small benthic recruits that are easy to identify and collect in intertidal habitats (Manríquez et al. 2004, 2008, 2009). Theoretically the long intra-capsular, pre-dispersal period at the natal site allows trace elements present in the seawater to be incorporated into the developing larval statoliths, and therefore permanently tag these structures with an elemental fingerprint of the birth location. Thus, the statoliths of new recruits should contain: (1) the elemental fingerprint of the natal site located in the statolith core; (2) a record of the environment through which the larvae have passed, in the area between the natal core and the statolith edge; and (3) because of the sedentary behavior of early settlers, the elemental signature of the recruitment site, located at the statolith edge.

Our previous studies of individual larval statoliths of Concholepas concholepas by laser ablation inductively coupled plasma mass spectrometry (LAICPMS) showed that detectable and different levels of multiple trace elements occurred in pre-hatching larvae collected between 2 geographically separate 
areas along the Chilean coast (Zacherl et al. 2003b). These results also suggested that natal signatures present in pre-release statoliths removed from egg capsules were comparable with the core signatures in statoliths removed from older larvae or recruits. Since Chile has a very long coast, latitudinal differences in upwelling, river discharges, terrigenous inputs, and land use are expected to have effects on the local availability of chemical components in coastal waters. Several perennial rivers drain the coastal region, supplying large quantities of terrigenous material from the mountains to the continental margin (Miller 1976). In general terms, the latitudinal differences include warmer waters, rich industrial and mining pollution, and an absence of river discharges in the north, while there is a distinct increase of river discharges and land use (i.e. agriculture and forestry) from the central to southern regions. We currently lack information regarding the chemical components present along the Chilean coast. However, for the purpose of the present study, the previously described variables are likely to generate considerable spatial variation in the chemical composition of seawater present in the 3 studied regions. Therefore, following the same criteria used in other studies (Zacherl et al. 2003b, Ruttenberg et al. 2005, Warner et al. 2005), we will assume that the deposition of trace elements in statoliths of $C$. concholepas will reflect local differences in the chemical and physical composition of seawater. The exact principles of elemental incorporation into gastropod statoliths are still unknown, and several factors potentially affect the incorporation. However, the most parsimonious way to relate seawater metal-tocalcium $(\mathrm{Me} / \mathrm{Ca})$ ratios with the elements incorporated into the statoliths is through an ion substitution reaction in which $\mathrm{Ca}^{2+}$ in the calcified structures, such as aragonitic statoliths, is replaced by divalent metals like $\mathrm{Sr}^{2+}$ and $\mathrm{Ba}^{2+}$ present in the seawater (see Zacherl et al. 2003a).

In the present study, we evaluated methods for measuring chemical signatures in pre- and postdispersal larval stages of Concholepas concholepas and examined patterns of geographic variability in those signatures across different regions of the Chilean coast. To this end, we sought to develop a reference collection of natal signatures across regions. Due to the heavy exploitation of the natural stock of $C$. concholepas in open-access areas along the Chilean coast, there are inherent difficulties in collecting egg capsules from the natural stock where adult specimens are exploited. Given this sampling problem, we did not attempt to explore detailed patterns of con- nectivity with these data. Instead, we evaluated the potential of chemical signatures in larval and recruit statoliths to be discriminatory for different geographic regions, and explored the possibility of classifying recruit origins based on the chemical data contained in the natal statolith. We hypothesized that, although larvae of C. concholepas have a potentially high dispersal range, it may be possible to distinguish between larval stocks along the Chilean coast, using the trace element composition of the natal core of pre-dispersal larvae and recruit statoliths.

\section{MATERIALS AND METHODS}

\section{Study regions}

We selected 3 regions along the coast of Chile with inherent differences in physical and chemical properties of the seawater (Fig. 1), and all subject to high levels of commercial exploitation of Concholepas concholepas. Sea-surface temperature (SST) decreases from north to south with clear seasonal variability between these 3 main regions: (1) northern $\left(25^{\circ} \mathrm{S}\right)$, with an average mean $( \pm \mathrm{SD})$ temperature of $17.03 \pm 1.23^{\circ} \mathrm{C}$ (Lagos et al. 2008); (2) central $\left(33^{\circ} \mathrm{S}\right)$, with an average mean temperature of $13.2 \pm$ $0.48^{\circ} \mathrm{C}$ (Lagos et al. 2005); (3) southern $\left(39^{\circ} \mathrm{S}\right.$ ) with an average mean temperature of $11.2 \pm 1.10^{\circ} \mathrm{C}$ (Lagos unpubl. data). In general, these fluctuations in SST along the Chilean coast are dominated by windinduced upwelling of cold waters (Strub et al. 1998). In addition, the input of river discharge into the coastal ocean also promotes a strong gradient along the coast (see Dávila et al. 2002): (1) in the northern region, there is an absolute lack of river discharge into Antofagasta Bay and surrounding areas; (2) from 30 to $35^{\circ} \mathrm{S}$ the rivers discharge at intermediate flow rates; and (3) in the southern region of our study (Valdivia), river discharges into coastal waters are much higher compared to those in the northern and central regions. Because river discharges represent one of the most important sources of alkalinity and other chemical elements for coastal waters (Bakker et al. 1996, Ternon et al. 2000), these differences may be reflected in the chemical compositions of statoliths of C. concholepas from the chosen study populations.

\section{Field collection of larvae}

Mature egg capsules of Concholepas concholepas can be recognized by their characteristic brown 


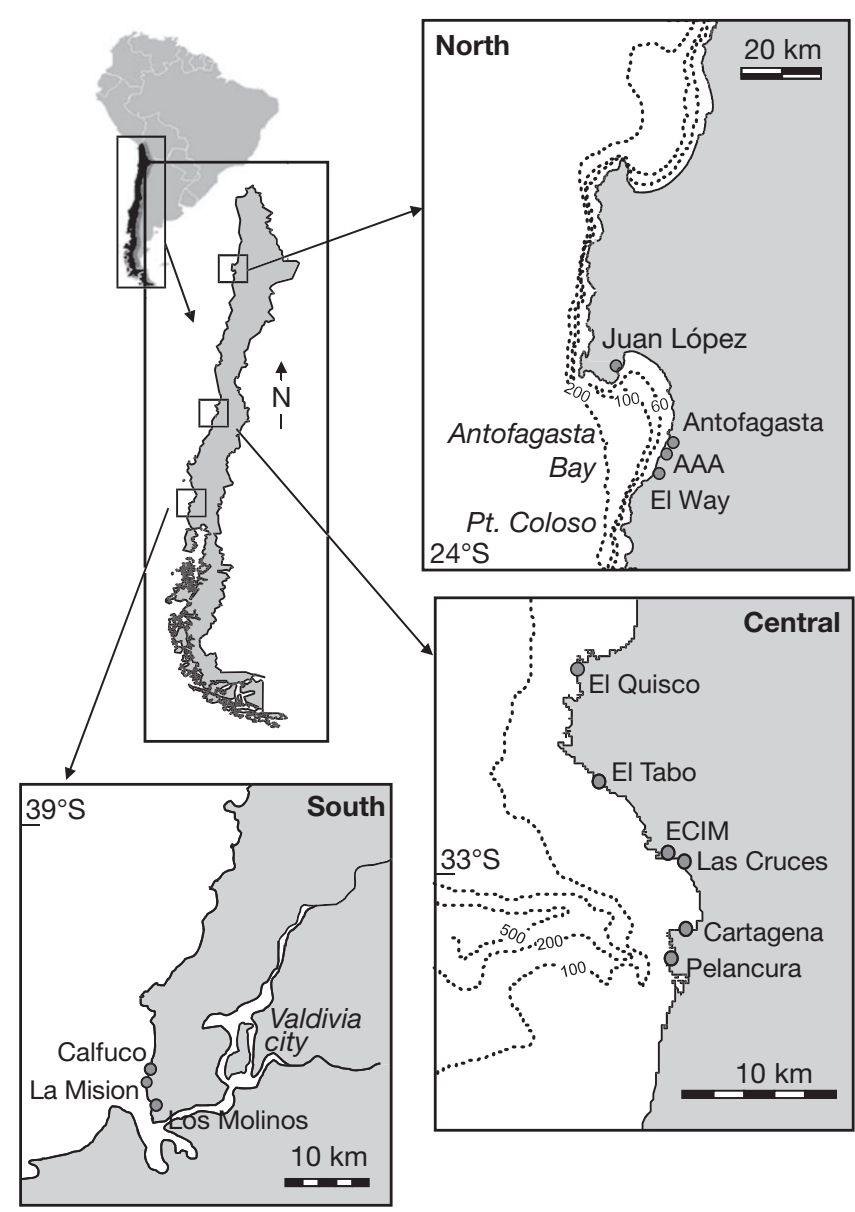

Fig. 1. Concholepas concholepas. Map indicating the 3 study regions and the locations where near-hatch egg capsules and recruits were sampled

coloration (containing larvae within a few days of hatching, hereafter near-hatch larvae; Manríquez \& Castilla 2001). These were collected from rocky intertidal habitats in 3 regions along the Chilean coast: Antofagasta Bay, northern Chile (4 locations: Antofagasta, AAA, El Way, and Juan López; October 2009); central Chile (1 location: El Quisco; July 2009); and southern Chile around Valdivia (2 locations: Los Molinos and Calfuco; July 2009) (Fig. 1). After collection, the egg capsules were labeled, frozen, and stored until statoliths were extracted (see following subsection). As a consequence of over-exploitation, natural populations of C. concholepas and their egg capsules were difficult to find in most rocky intertidal environments (Manríquez \& Castilla 2001). This difficulty limited the sample size and substantially reduced the spatial degrees of freedom inside each sampling region, thus reducing the statistical power of our study.

\section{Field collection of recruits}

In the months following egg capsule collection, recruits of Concholepas concholepas were sampled in rocky intertidal habitats within the geographical locations where egg-capsules were obtained (Fig. 1). We employed a 3 mo interval between field collection of egg capsules and recruits in each region to account for the average pelagic larval duration of C. concholepas, and thus to ensure that recruits originated from the same birth cohorts as the larvae (DiSalvo 1988, Martínez \& Navarrete 2002, Manríquez et al. 2008, Manríquez unpubl. data). After collection, recruits were labeled, frozen, and stored until the statoliths were extracted (see next subsection).

\section{Extraction and preparation of statoliths for ICPMS analysis}

Egg-capsules of Concholepas concholepas were defrosted for ca. $20 \mathrm{~min}$ and then dissected to release larvae. Statoliths of larvae and recruits were extracted using a modified version of the protocols described by Zacherl et al. (2003b). Recruits with a weight lower than $0.01 \mathrm{~g}$ and larvae from egg capsules were suspended in an equal volume mixture of $35 \% \mathrm{H}_{2} \mathrm{O}_{2}$ buffered in $\mathrm{NaOH}(0.1 \mathrm{~N})$ for 20 to $30 \mathrm{~min}$ at $100^{\circ} \mathrm{C}$. Recruits heavier than $0.01 \mathrm{~g}$ were dissected out of the shell, the digestive and excretory organs removed, and the remaining soft tissue was then suspended in the $\mathrm{H}_{2} \mathrm{O}_{2}$ solution as above. The released larval statoliths were collected, rinsed 3 times in ultrapure water ( $\mathrm{N}$-pure, resistivity >18.1 M $\Omega$ ) in acid-rinsed glassware, and then pipetted onto a transparent $1.8 \times 1.8 \mathrm{~cm}$ square of polycarbonate sheeting that had been cleaned by $4 \mathrm{~d}$ of submersion in ultrapure water. The larval statoliths were then air dried in a laminar flow hood (HEPA-filter class 100) and mounted on double-sided tape (Scotch ${ }^{\mathrm{TM}}$; Zacherl et al. 2003b). Following this procedure, each egg capsule yielded ca. 60 to 100 larval statoliths. For recruits, we mounted only one of the 2 statoliths on a polycarbonate slide using low-viscosity thermoplastic epoxy resin (Epo-Thin epoxy resin, Buehler ${ }^{\mathrm{TM}}$ ). The statoliths were then polished using 9, 3, and $1 \mu \mathrm{m} 3 \mathrm{M}^{\mathrm{TM}}$ diamond polishing paper with a Model 920 lapping and polishing machine (SouthBay ${ }^{\mathrm{TM}}$ ) to expose the statolith core. We left at least $5 \mu \mathrm{m}$ between the polished surface and the core to ensure that the core was not removed during the preablation procedures and that all material associated with the natal core was sampled. All extractions and 
mountings of statoliths were conducted at the Laboratorio Costero de Recursos Acuáticos at Calfuco on the coast near Valdivia. The extracted statoliths were maintained in a dust-free environment provided by a laminar flow cabinet and stored in acid-washed polyethylene vials in order to minimize sources of contamination during their preparation for transportation to the University of California Santa Barbara where trace element analysis took place. All the glassware material used in the statolith extraction and mounting was cleaned prior to use with $1 \mathrm{~N} \mathrm{HCl}$ (submersion for $24 \mathrm{~h}$ ) and rinsed 5 times with ultrapure water.

\section{Trace element analysis}

Mounted statoliths were analyzed on a Finnigan Element 2 sector field inductively coupled plasma mass spectrometer with a New Wave Nd:YAG deep ultraviolet $(213 \mathrm{~nm}$ ) laser ablation system (with the laser pulsed at $10 \mathrm{~Hz}$ ) for chemical analysis. The laser ablation system was outfitted with a helium aerosol carrier gas system in order to increase sensitivity through enhanced production and transfer of ablated particles to the ICPMS (Swearer et al. 1999, Zacherl et al. 2003b). For the purposes of the present study, we defined the natal statolith in near-hatch larvae as all material contained in the statolith primordium as well as other statolith material deposited while the developing larva remained inside the attached egg capsule (see Fig. 2a). This portion corresponds to the material formed at the spawning site (larval origin) and does not require further preparation. Because of their small size (ca. $10 \mu \mathrm{m})$, statoliths extracted from near-hatch larvae were completely consumed in a single laser ablation, with 5 statoliths ablated per egg capsule. To obtain ontogenetically similar trace elemental information from the statoliths removed from the recruits, we conducted a single ablation centered on the natal core. The core can be identified visually by a prominent checkmark that is laid down at hatching. The checkmark can be seen in larval statoliths just after hatching under laboratory conditions, and is present at the same statolith radius in fieldcollected competent larvae (P.H. Manríquez \& S.P. Galaz unpubl. data). There is a similar checkmark at the edge of the statolith of newly settled specimens collected in the field (P.H. Manríquez \& S.P. Galaz unpubl. data). This suggests that the 2 checkmarks can be used to denote 2 major events in the early life of Concholepas concholepas: hatching and settlement. This allowed us to visualize in recruits of this species 3 distinct regions for sampling: (1) the statolith core, the region located in the center of the statolith that comprised the natal signatures; (2) the mid-area, the region with material deposited during the pelagic phase prior to settlement; and (3) the statolith edge, the region located next to the periphery of the statoliths containing material deposited during the sedentary benthic phase after settlement (Fig. 2b). Therefore, in recruit

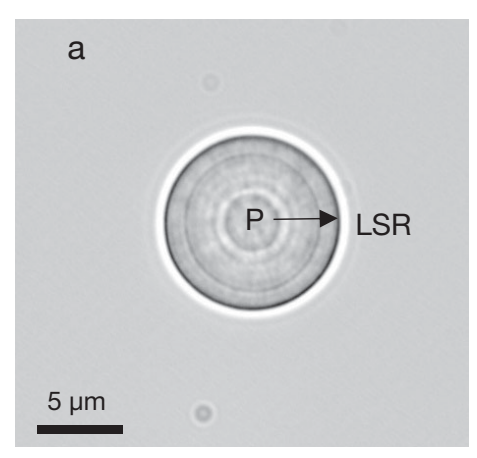

Fig. 2. Concholepas concholepas. Photographs of: (a) a near-hatch larva in immersion oil showing the primordium (P) at the center of the natal core and the larval statolith radius (LSR); (b) an unpolished statolith of a recruit specimen showing the primordium (P), settlement checkmark (SC), and the recruit statolith radius (RSR); and (c) a polished resin-embedded statolith with the laser ablation pits at the recruit statolith natal core (NC), midareas (MA), and edge areas (EA). (d) Mean distance (+SE) from the P to the LSR, and to MA, EA, and RSR of specimens collected in southern, central, and northern Chile
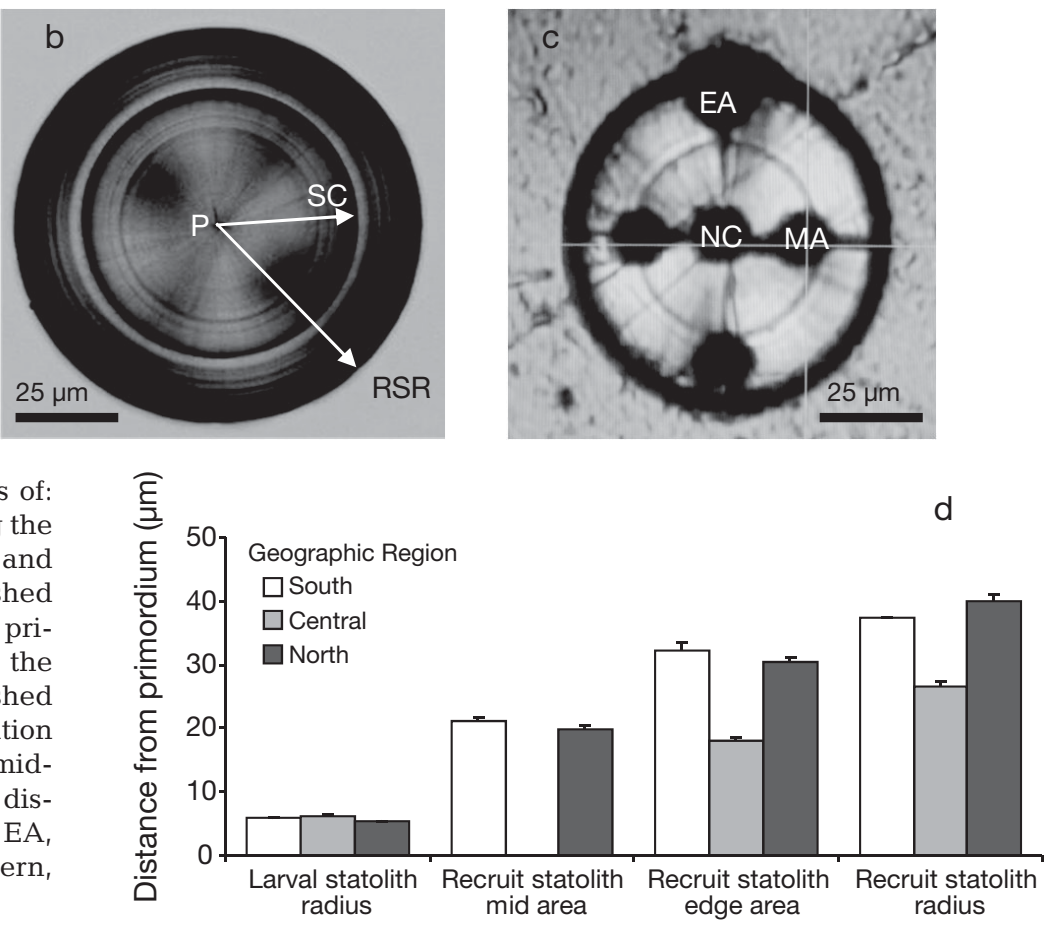
Table 1. Concholepas concholepas. Summary of element ratios derived from each statolith extracted from near-hatch larvae and recruits collected from northern, central, and southern regions of Chile. Sampling in northern Chile during October 2009 (egg capsules) and January 2010 (recruits); in central Chile during July 2009 (egg capsules) and October 2009 (recruits); and in southern Chile during July 2009 (egg capsules) and October 2009 (recruits). The sampling seasons were conducted matching the peak abundances of egg capsules and recruits within each region (Manríquez \& Castilla 2001, Martínez \& Navarrete 2002, Manríquez et al. 2008, P. H. Manríquez unpubl. data)

\begin{tabular}{|c|c|c|c|c|}
\hline Region & Sites & $\begin{array}{l}\text { Samples } \\
\text { (n) }\end{array}$ & $\begin{array}{c}\text { Statoliths } \\
\text { ablated }\end{array}$ & $\begin{array}{l}\text { Trace elements } \\
\text { sampled }\end{array}$ \\
\hline $\begin{array}{l}\text { Larvae } \\
\text { South }\end{array}$ & $\begin{array}{l}\text { Calfuco } \\
\text { Los Molinos }\end{array}$ & $\begin{array}{l}5 \\
5\end{array}$ & $\begin{array}{l}25 \\
25\end{array}$ & $\begin{array}{c}{ }^{24} \mathrm{Mg} /{ }^{48} \mathrm{Ca} \text { and }{ }^{86} \mathrm{Sr} /{ }^{48} \mathrm{Ca} \\
\text { in mmol mol }\end{array}$ \\
\hline Central & El Quisco & 5 & 25 & \\
\hline North & $\begin{array}{l}\text { El Way } \\
\text { AAA } \\
\text { Antofagasta } \\
\text { Juan López }\end{array}$ & $\begin{array}{l}4 \\
4 \\
4 \\
1\end{array}$ & $\begin{array}{c}20 \\
20 \\
20 \\
5\end{array}$ & \\
\hline $\begin{array}{l}\text { Recruits } \\
\text { South }\end{array}$ & $\begin{array}{l}\text { Calfuco } \\
\text { La Misión }\end{array}$ & $\begin{array}{l}5 \\
6\end{array}$ & $\begin{array}{l}5 \\
6\end{array}$ & $\begin{array}{c}{ }^{138} \mathrm{Ba} /{ }^{48} \mathrm{Ca} \text { and }{ }^{208} \mathrm{~Pb} /{ }^{48} \mathrm{Ca} \text {, } \\
\text { in } \mu \mathrm{mol} \mathrm{mol} \mathrm{mol}^{-1}\end{array}$ \\
\hline Central & $\begin{array}{l}\text { Pelancura } \\
\text { Cartagena } \\
\text { Las Cruces } \\
\text { ECIM } \\
\text { El Tabo }\end{array}$ & $\begin{array}{l}5 \\
3 \\
6 \\
5 \\
1\end{array}$ & $\begin{array}{l}5 \\
3 \\
6 \\
5 \\
1\end{array}$ & \\
\hline North & $\begin{array}{l}\text { El Way } \\
\text { AAA } \\
\text { Antofagasta } \\
\text { Juan López }\end{array}$ & $\begin{array}{l}5 \\
5 \\
5 \\
5\end{array}$ & $\begin{array}{l}5 \\
5 \\
5 \\
5\end{array}$ & \\
\hline
\end{tabular}

National Institute of Standards and Technology (NIST 612) which allowed for quantification and correction of instrument drift. Estimates of precision as coefficients of variation among replicate analyses of the NIST material, described as \%RSD (percent relative standard deviation), were $2.49 \%$ for $\mathrm{Mg} / \mathrm{Ca}, 2.36 \%$ for $\mathrm{Sr} / \mathrm{Ca}, 1.85 \%$ for $\mathrm{Ba} / \mathrm{Ca}$, and $3.59 \%$ for $\mathrm{Pb} / \mathrm{Ca}$. Because sampled material is mixed with aspirated $1 \% \mathrm{HNO}_{3}$ in the introduction system, we blank-subtracted statolith intensity values from those of a $1 \% \mathrm{HNO}_{3}$ sample analyzed before each statolith. We characterized the instrument limits of detection as $3 \times \mathrm{SD}$ of the blanks and calculated ratios to mean Ca intensities to obtain a Me/Ca detection limit of $1.052 \mathrm{mmol} \mathrm{mol}^{-1}$ for $\mathrm{Mg} / \mathrm{Ca}, 1.767$ $\mathrm{mmol} \mathrm{mol}{ }^{-1}$ for Sr/Ca, $0.206 \mu \mathrm{mol} \mathrm{mol}^{-1}$ for

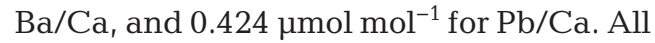
ablations were conducted during July of 2010 in the Marine Science Institute Analytical Facility, University of California, Santa Barbara, USA.

We took special care to avoid ablating nearby areas to minimize cross elemental contamination between different areas within each statolith. We ablated the natal statolith of near-hatched larvae and the natal core of recruit statoliths (Fig. 2a,c) using the ablation system set with the

statoliths, the core ablation was followed by 2 additional ablations at increasing distances from the core: (1) the mid-area ablation, representing the pelagic dispersal period; and (2) an ablation along the edge, representing the period following settlement. Each ablation consisted of 8 laser pulses of $0.1 \mathrm{~mJ}$ at $10 \mathrm{~Hz}$ that created a pit $12 \mu \mathrm{m}$ in diameter and $\sim 10 \mu \mathrm{m}$ deep. The elements sampled included magnesium $\left({ }^{24} \mathrm{Mg}\right)$, calcium $\left({ }^{48} \mathrm{Ca}\right)$, strontium $\left({ }^{87} \mathrm{Sr}\right)$, barium $\left({ }^{138} \mathrm{Ba}\right)$, and lead $\left({ }^{208} \mathrm{~Pb}\right)$ in low-resolution mode (resolving power: $\mathrm{R}=300$ ) with a correction for ${ }^{24} \mathrm{Mg}$ to account for ${ }^{48} \mathrm{Ca}^{++}$interference (see Table 1 for a summary of analyzed elements, sample size for each region, and study sites). We report each element as a ratio to $\mathrm{Ca}$ (i.e. $\mathrm{Me} / \mathrm{Ca}$ ), and corrected for mass-bias using calibration standards with known element-toCa ratios (Ruttenberg et al. 2005, Warner et al. 2005). We bracketed every 4 samples with solution calibration standards and ran blanks before each sample. Samples were randomized across and within blocks prior to analysis. To maintain instrument precision, we analyzed solid glass standard material from the same pit size $(12 \mu \mathrm{m})$. This size is similar to the diameter of the natal statolith of near-hatch larvae of Concholepas concholepas (ca. $10 \mu \mathrm{m}$; Fig. 2a), and ablates all of the natal statolith material. We also ablated mid- and edge areas of the recruit statoliths using the same pit size (Fig. 2c). However, because of their relatively small size $(54.97 \pm 5.33 \mu \mathrm{m}$ in diameter, mean $\pm \mathrm{SD} ; \mathrm{n}=20$ ), the statoliths extracted from recruits collected in central Chile were only ablated in the core and edge areas. The larger sizes of the statoliths from northern $(82.14 \pm 9.55 \mu \mathrm{m}$, mean $\pm \mathrm{SD}$; $\mathrm{n}=20)$ and southern $(77.17 \pm 12.17 \mu \mathrm{m}$, mean $\pm \mathrm{SD} ; \mathrm{n}$ $=40$ ) sites permitted ablations to be made in all 3 positions (Fig. 2c). Recruit statoliths of northern origin were larger than those of southern origin because recruits collected in the north had a larger body size.

\section{Statistical analyses}

Elemental concentration in statoliths is expressed as $\mathrm{Me} / \mathrm{Ca}$ in millimoles per mole or micromoles per 
mole. Any concentration below the limits of detection (LOD) that was zero or negative after the subtraction of the blank concentration was dropped from further analysis, while positive values above and below the LOD were retained (Warner et al. 2009). All measured concentrations of $\mathrm{Zn}$ and most of $\mathrm{Pb}$ were sparse and highly variable (see 'Results'; Table 2) so they were dropped from further analysis. Thus, we used the concentrations of $\mathrm{Mg}, \mathrm{Sr}, \mathrm{Ba}$, and in some instances $\mathrm{Pb}$ (Table 2) for further statistical analyses.

In order to detect regional differences in the concentrations of particular elements and multi-element fingerprints in near-hatch larval statoliths and in different areas within recruit statoliths (natal core, mid, and edge areas), we performed univariate and multivariate analyses of variance (ANOVA, MANOVA). We also compared univariate and combined elemental signatures between larval statolith and recruit cores by region. We used MANOVA models to test for spatial differences in multi-element fingerprints using Pillai's trace as the test statistic (Warner et al. 2009). Because all statoliths from a given egg capsule are not truly independent due to potential maternal effects and the fact that encapsulated larvae develop under identical conditions within the egg capsule, we averaged the data from the ablations performed within the same egg capsule sample. Tukey's honestly significant difference (HSD) test was used to identify post hoc differences $(\alpha=0.05)$ in $\mathrm{Me} / \mathrm{Ca}$ concentrations in the corresponding test. $\log _{10}$ transformation of the data was sufficient to meet ANOVA assumptions, which were evaluated over the residuals of the corresponding model. We also used quadratic discriminant function analyses (DFA) on egg-capsule data to visualize spatial differences between different sampling regions using SYSTAT V14, and to examine reclassification success for egg capsules from those regions using Matlab ${ }^{\circledR}$ V7.1. Given the different sample sizes across regions, we used empirical priors in the DFA. We cross-validated the reclassification success using jackknife ('leave one out') procedures implemented using the statistical toolbox in Matlab. Significance of reclassification success was estimated using a randomization procedure with 5000 runs, as described by White \& Ruttenberg (2007). Similar DFA procedures were done over recruit core and edge areas to visualize differences in chemical signatures between regions. We used the larval statolith chemistry data as a training dataset in a DFA to classify the recruits based on the statolith natal core data. Because the larvae and recruits were sampled sparsely over large spatial scales, we did not attempt to assign the recruits back to any particular site of origin. Rather, we asked whether data from recruits fell within the same discriminant space as the data from larvae from a particular geographic region, indicating a region of origin rather than a specific location within each region.

\section{RESULTS}

While larval statoliths are small (Fig. 2a) and completely ablated by LA-ICPMS, recruit statoliths are relatively large, spherical, and exhibit distinguishable areas from the natal primordium to the edge, demarcated by numerous check marks signifying lifehistory transitions (Fig. 2b). Statoliths of near-hatch larvae and recruits of Concholepas concholepas from the 3 collection regions along the coast had reliably detectable concentrations for 3 elements $(\mathrm{Mg}, \mathrm{Sr}$, and $\mathrm{Ba}$; Table 2). In the case of $\mathrm{Pb}$, only $23 \%$ of the samples from recruit cores showed levels above the LOD. Therefore, although $\mathrm{Pb}$ was included in univariate analysis (ANOVA), the differences in sample size did not allow for its inclusion in multivariate analysis using DFA (see following subsection).

Table 2. Concholepas concholepas. Summary of total number of statoliths extracted, number of ablations conducted in the natal core of near-hatch larvae and in the core, mid-, and edge areas of recruit statoliths, percentage of samples recording detectable levels of each element, and percentage of samples having Me/Ca concentrations greater than the limits of detection (LOD). Detectable levels were those in which counts per second of a particular element were positive in LA-ICPMS analyses. LODs were determined by analyzing a blank solution and were characterized as $3 \times$ SD of the blank and calculated relative to mean Ca intensities (see 'Materials and methods')

\begin{tabular}{|c|c|c|c|c|c|c|c|c|c|c|}
\hline \multirow[t]{2}{*}{ Sample } & \multirow[t]{2}{*}{$\begin{array}{l}\text { No. of } \\
\text { statoliths }\end{array}$} & \multirow[t]{2}{*}{$\begin{array}{l}\text { No. of } \\
\text { ablations }\end{array}$} & \multicolumn{4}{|c|}{$\begin{array}{l}\text { Percent of samples } \\
\text { with detectable levels }\end{array}$} & \multicolumn{4}{|c|}{$\begin{array}{c}\text { Percent of samples in } \\
\text { which concentration >LOD }\end{array}$} \\
\hline & & & $\mathrm{Mg}$ & $\mathrm{Sr}$ & $\mathrm{Ba}$ & $\mathrm{Pb}$ & $\mathrm{Mg}$ & $\mathrm{Sr}$ & $\mathrm{Ba}$ & $\mathrm{Pb}$ \\
\hline Natal statolith & 139 & 139 & 100 & 100 & 99 & 98 & 100 & 100 & 99 & 98 \\
\hline Recruit natal core & 51 & 51 & 100 & 98 & 100 & 78 & 96 & 98 & 98 & 23 \\
\hline Recruit mid-area & 51 & 66 & 100 & 100 & 100 & 100 & 100 & 100 & 97 & 14 \\
\hline Recruit edge area & 51 & 110 & 100 & 100 & 100 & 93 & 100 & 100 & 96 & 57 \\
\hline
\end{tabular}



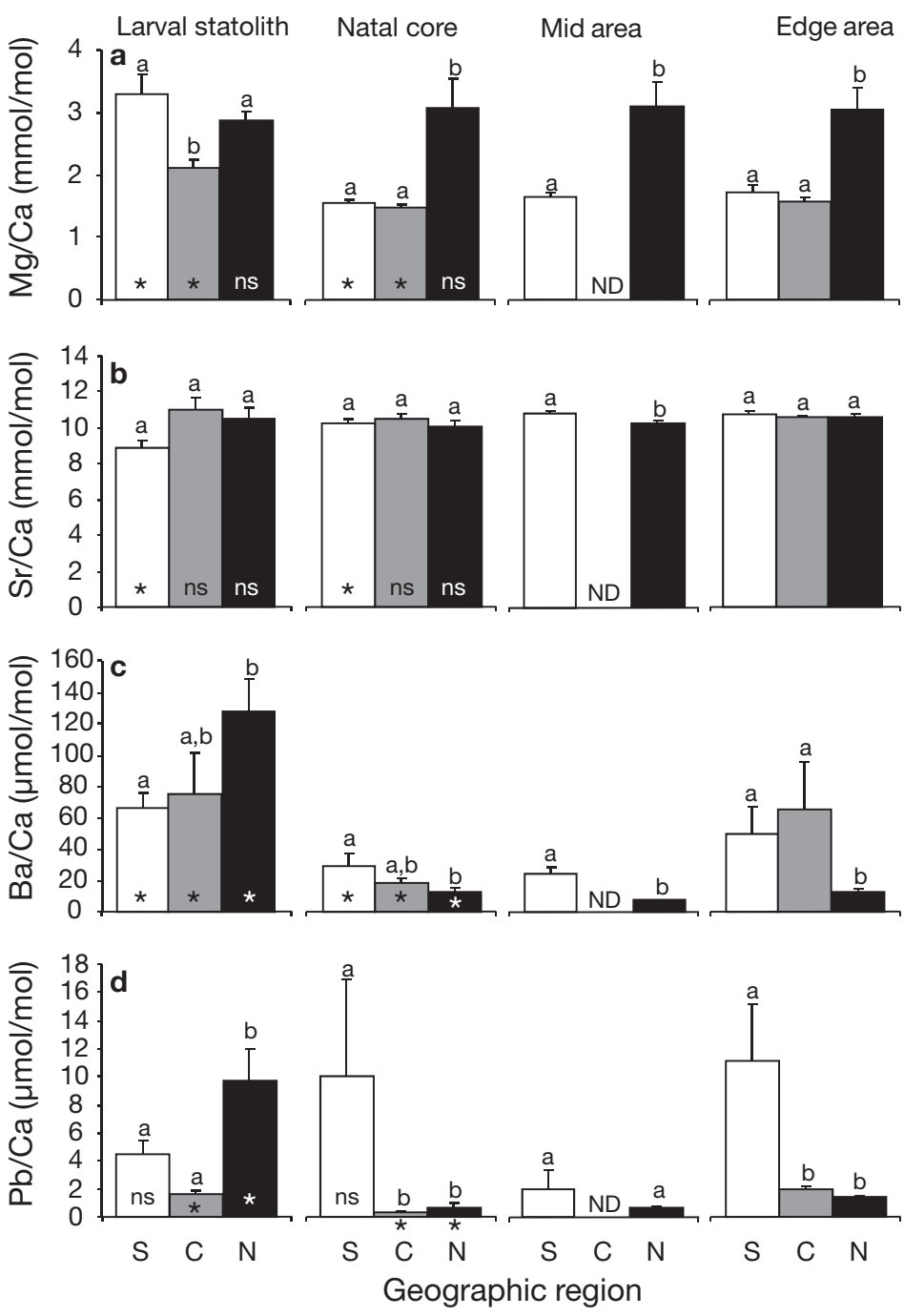

Fig. 3. Concholepas concholepas. Mean concentration (+SE) of trace elements recorded in larval natal statoliths and in natal core, mid-, and edge areas of recruit statoliths collected in southern (S), central (C) and northern (N) Chile. Different letters above each bar represent significant differences $(\mathrm{p}<$ 0.05) in among-region comparisons using ANOVA and Tukey's HSD as a post hoc test. Asterisks inside and at the bottom of each bar indicate significant differences between larval statolith and natal core of specimens collected in the same region; ns: no significant differences in paired comparison; ND: no data

\section{Larval natal statoliths}

With the exception of $\mathrm{Sr} / \mathrm{Ca}$ signatures, trace element concentrations of $\mathrm{Mg} / \mathrm{Ca}, \mathrm{Ba} / \mathrm{Ca}$, and $\mathrm{Pb} / \mathrm{Ca}$ recorded in the natal statolith of near-hatch larvae of Concholepas concholepas exhibited significant variations between the 3 geographically separate regions (ANOVA, p < 0.05), showing significant increases in concentration in the northern region compared to the southern region for $\mathrm{Ba} / \mathrm{Ca}$ and

$\mathrm{Pb} / \mathrm{Ca}$ (Tukey's HSD, p < 0.05). However, Mg/Ca levels were similar between southern and northern regions (Fig. 3). Using combined information from all elements detectable in the natal statolith of near-hatch larvae in a MANOVA, regions were significantly different from one another (Pillai's trace $=0.932, F_{8,46}=5.01, p<0.001$ ). The regional differences in chemical signatures in the natal statoliths of near-hatch larvae of C. concholepas can be also visualized in the DFA space, which was mainly driven by levels of $\mathrm{Mg}, \mathrm{Sr}$, and Ba in both Functions 1 and 2, with a $68 \%$ crossvalidated (jackknifed) classification success $(\mathrm{p}=$ 0.006; Fig. 4a).

\section{Recruit statolith natal cores}

Trace element concentrations recorded in the natal core of recruit statoliths exhibited a significant increase in $\mathrm{Mg} / \mathrm{Ca}$ in the northern region and increases in $\mathrm{Pb} / \mathrm{Ca}$ and $\mathrm{Ba} / \mathrm{Ca}$ in the southern region with respect to the northern region (ANOVA, Tukey's HSD, $\mathrm{p}<0.05$ ), while $\mathrm{Sr} / \mathrm{Ca}$ exhibited similar levels across regions (Fig. 3). Combined concentrations of all trace metals recorded in recruit natal cores were significantly different among regions $($ MANOVA, Pillai's trace $=$ $\left.0.653, F_{8,68}=4.116, \mathrm{p}<0.001\right)$. Regional differences visualized in the DFA bidimensional space were also driven by levels of $\mathrm{Mg}, \mathrm{Sr}$, and $\mathrm{Ba}$ in both Functions 1 and 2, and with $52 \%$ cross-validated (jackknifed) classification success $(\mathrm{p}=$ 0.0036; Fig. 4b).

\section{Recruit statolith mid-areas}

Trace element concentrations recorded in recruit statolith mid areas of Concholepas concholepas exhibited a significant increase in $\mathrm{Sr} / \mathrm{Ca}$ and $\mathrm{Ba} / \mathrm{Ca}$ in the southern region and decrease in $\mathrm{Mg} / \mathrm{Ca}$ in the northern region (ANOVA, Tukey's HSD, $\mathrm{p}<0.05$ ), while $\mathrm{Pb} / \mathrm{Ca}$ was similar between southern and northern regions (Fig. 3). Average concentrations of trace metals in mid-areas of recruit statoliths were significantly different between regions $\left(\right.$ MANOVA, Pillai's trace $=0.621, F_{4,19}=7.793, \mathrm{p}<$ 0.001 ), and this pattern was driven primarily by differences in Mg, Sr, and Ba (Fig. 3). However, DFA applied over these chemical data exhibited a non-significant pattern of discrimination among regions (52\% [jackknifed] cases correctly classified, $\mathrm{p}=0.349$ ). 

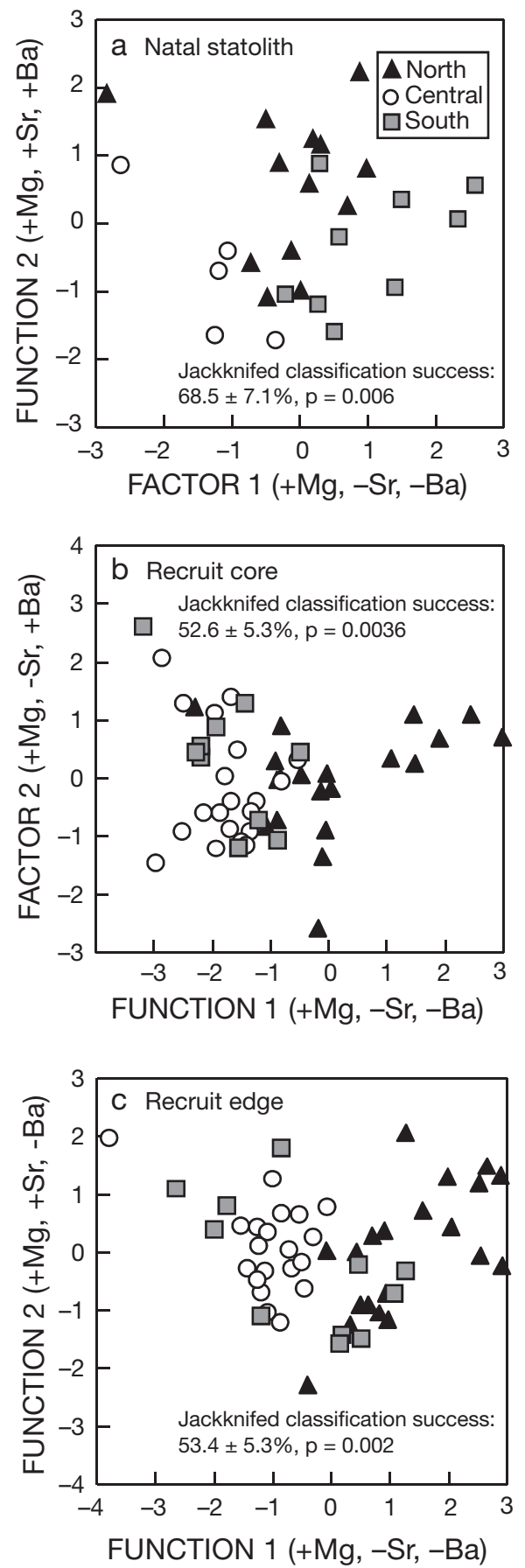

Fig. 4. Concholepas concholepas. Discriminant function analysis generated using $\mathrm{Mg} / \mathrm{Ca}, \mathrm{Sr} / \mathrm{Ca}$, and $\mathrm{Ba} / \mathrm{Ca}$ of: (a) natal statoliths, (b) recruit natal core, and (c) edge areas. The jackknifed reclassification success $(\%$, mean \pm SD) and significance are given within each plot

\section{Recruit statolith edge area}

Trace element concentrations recorded in recruit statolith edges of Concholepas concholepas exhib- ited a significant decrease in $\mathrm{Ba} / \mathrm{Ca}$ and $\mathrm{Pb} / \mathrm{Ca}$, and a significant increase in $\mathrm{Mg} / \mathrm{Ca}$ levels in the northern region (ANOVA, Tukey's HSD, p < 0.05). Similar concentrations of $\mathrm{Sr} / \mathrm{Ca}$ were observed in the 3 regions (Fig. 3). Average concentrations of trace metals in the statolith edge area were significantly different among regions (MANOVA, Pillai's trace $=0.946$, $\left.F_{8,84}=9.423, \mathrm{p}<0.001\right)$, and this pattern was driven primarily by differences in $\mathrm{Mg}, \mathrm{Ba}$, and $\mathrm{Pb}$ (Fig. 3). This edge area signature exhibited a significant discrimination among regions of origin, showing $53.4 \%$ cross-validated (jackknifed) reclassification success $(p=0.0002 ;$ Fig. $4 \mathrm{c})$.

\section{Larval statolith - recruit natal cores}

When comparing the concentrations of trace metals between the larval statolith and recruit cores within each region using MANOVA, we found significant differences in southern (Pillai's trace $=0.762, F_{4,8}=$ 6.418, $\mathrm{p}=0.013$ ), central (Pillai's trace $=0.753, F_{4,18}=$ 13.703, p < 0.001), and northern regions (Pillai's trace $\left.=0.836, F_{4,26}=33.014, \mathrm{p}<0.001\right)$. These differences were driven primarily by significant variations in the levels of $\mathrm{Mg} / \mathrm{Ca}, \mathrm{Sr} / \mathrm{Ca}$, and $\mathrm{Ba} / \mathrm{Ca}$ in the southern region; $\mathrm{Mg} / \mathrm{Ca}, \mathrm{Ba} / \mathrm{Ca}$, and $\mathrm{Pb} / \mathrm{Ca}$ in the central region; and $\mathrm{Ba} / \mathrm{Ca}$ and $\mathrm{Pb} / \mathrm{Ca}$ in the northern region (ANOVA, Tukey's HSD, $\mathrm{p}<0.05$; Fig. 3). In general, regardless of the geographic region, we observed an enrichment of Ba in larval statoliths with respect to recruit natal cores (Fig. 3).

Natal statoliths and recruit cores exhibited qualitatively similar geographic variation for $\mathrm{Mg} / \mathrm{Ca}$ and $\mathrm{Sr} / \mathrm{Ca}_{1}$ in terms of the rank order of concentrations among regions (Fig. 3). However, qualitative patterns of geographic variation between natal statoliths and recruit cores did not match for $\mathrm{Ba} / \mathrm{Ca}$ or $\mathrm{Pb} / \mathrm{Ca}$, and, for both elements, concentrations were highest in the southern region for natal statoliths, but did not show this pattern for recruit cores (Fig. 3). Recruit natal cores were classified based on discriminant functions generated using the concentrations of trace elemental composition found in the natal statolith of pre-hatch larvae (Fig. 5). Regional patterns in chemical signatures among larval and recruit statolith samples were also evident when we used larval data as a training data set in a DFA to classify the recruit natal core samples across regions (Pillai's trace $=0.639, F_{6,48}=$ $3.758, \mathrm{p}=0.004)$. However, despite the high success in reclassification of larval statolith data to the region where they were collected ( $77 \%$ of jackknifed classification success), only $22 \%$ of the recruit natal cores 


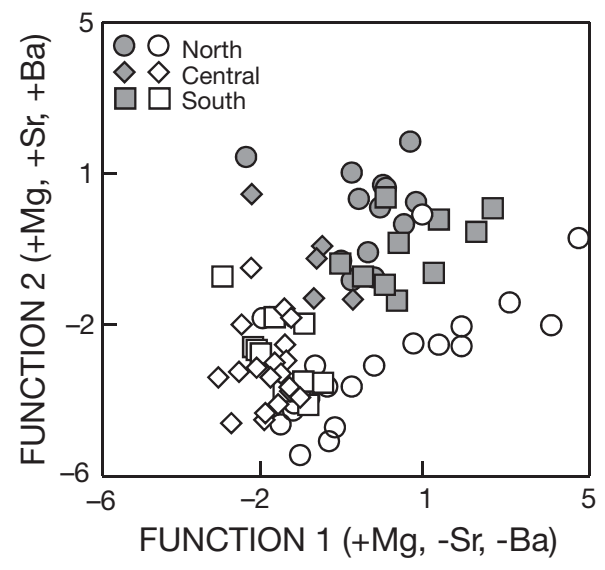

Fig. 5. Concholepas concholepas. Discriminant functions generated using $\mathrm{Mg}, \mathrm{Sr}$, and $\mathrm{Ba}$ of larval statoliths (filled symbols) and then used to classify recruit cores (open symbols). Jackknife reclassification success of the larval statoliths to the region where they were collected is $77 \%$. Using these discriminant functions, only $22 \%$ of the recruits were correctly reclassified, which, with few exceptions, lie at the borders of the discriminant function analysis space generated by larvae

were classified to the region where they were collected. In general, data on recruit natal cores tended to fall relatively close, but did not overlap with the discriminant space of the geographically corresponding larval statoliths (Fig. 5).

\section{DISCUSSION}

Our study was able to acquire very small statoliths from 2 distinct stages of the early ontogeny of Concholepas concholepas (i.e. near-hatch larvae and recruits) and obtain chemical signatures of the trace elements present in those statoliths. The statoliths were collected at 3 widely separated locations along the Chilean coast which allowed us to explore spatial discrimination at regional scales using trace elements of near-hatch larvae, coupled with an exploration of classification of recruit natal cores given the chemical signatures present in statoliths of nearhatch larvae. The near-hatch larval statoliths recorded geographically distinct natal signatures allowing potential source regions to be identified in post-settlement individuals. Although the elemental signatures obtained from recruit statolith natal cores may be contaminated or diluted with non-core ablated material, we recorded in those cores 3 trace element signature patterns that resembled the predispersal natal signatures recorded in near-hatch larval statoliths on a regional basis.
Elemental signatures obtained from recruit midareas show signature patterns similar to those recorded on near-hatch statoliths. However, the analysis of the mid-area samples was unable to significantly discriminate between the potential source regions. This is likely due to the very low concentrations of $\mathrm{Pb}$ in the mid-area samples relative to levels seen in the cores and edges (Fig. 3); only $14 \%$ of the samples from the mid-area had $\mathrm{Pb}$ levels above the LOD (Table 2). Because of the availability of a larger suite of elements, it appears that larval statolith and recruit natal cores are the best areas within the statoliths to successfully conduct spatial discrimination between regions in Concholepas concholepas.

Based on statolith microchemical data, reclassification success to the collection region for near-hatch larvae and recruit cores were 68.5 and $52.6 \%$, respectively. Those values are relatively close to the range described in the gastropod Kelletia kelletii, with $70 \%$ of the statoliths being accurately assigned to the collection regions (Koch 2008). Moreover, our values are below or close to values reported in fish otolith chemistry studies $-80 \%$ in rockfish (Chittaro et al. 2010), 50 to $88 \%$ in weakfish (Thorrold et al. 1998), and 50 to $70 \%$ in reef fish (Cook 2011) — but fall below the $90 \%$ correctly classified in studies using trace elemental fingerprint of mytilid mussel shells (Becker et al. 2005). This suggests that the use of statolith chemistry to investigate population structure in species with life histories like Concholepas concholepas is adequate.

The results here cover a large geographic range of sampling and show that some of the regional differences in elemental signatures seen in pre-dispersal larvae persisted into later ontogenetic stages and in distinct areas within recruit statoliths (core, mid-, and edge areas). Moreover, the chemistry of the natal cores from all recruits in any given region was distinct from the other 2 regions. This suggests that there are discrete adult populations at these geographic scales. The regional differences in elemental signatures among samples collected over this large range may be explained by differential elemental incorporation rates influenced by factors such as different ambient elemental concentrations, different upwelling regimens, nutrient-rich rainwater runoff, and temperature, among other factors (Zacherl 2005, Warner et al. 2009). Coastal upwelling along the Chilean coast results in low water temperatures, high salinity, high nutrients, and increased primary productivity (Strub et al. 1998). In particular, barium is broadly associated with cooling events during upwelling (Zacherl 2005), and the reduction in $\mathrm{Ba} / \mathrm{Ca}$ 
ratios in the natal core of recruit statoliths collected from the northern region may be interpreted in relation to the presence of a persistent upwelling shadow inside Antofagasta Bay (Castilla et al. 2002, Lagos et al. 2008). This agrees with the significant reduction in $\mathrm{Ba} / \mathrm{Ca}$ from southern to northern recruit statoliths, and might be associated with the negative effect of temperature in the incorporation of $\mathrm{Ba}$ as has been reported in studies conducted in gastropods (Zacherl et al. 2003a, Zumholz et al. 2007, Lloyd et al. 2008) and bivalves (Carson 2010). Interestingly, pre-hatch larval statoliths (where individuals are fixed in place) do not show this pattern, and instead show a significant increase of the $\mathrm{Ba} / \mathrm{Ca}$ ratio from southern to northern populations. This suggests that the incorporation of $\mathrm{Ba}$ is not only modulated by seawater temperature. Other mechanisms such as diet can add considerable variation in the elemental incorporation into statoliths (see below). However, as consequence of the low number of samples with concentrations of $\mathrm{Pb}$ greater than the LODs, attempts to interpret or explain the regional differences found in the present study that are based on $\mathrm{Pb}$ are too speculative.

As marine organisms deposit material onto mineralized structures such as statoliths, trace elements sensitive to shifts in water properties can be incorporated into the calcium carbonate matrix, preserving records of local environmental conditions (Takesue \& van Geen 2004). The observed spatial pattern of the concentrations of trace elements recorded by ablation of the larval statolith, as well as in the natal cores, mid-areas, and edge areas of recruit statoliths, indicates significant geographic variation in elemental signatures. This might reflect the different environmental availability of those elements across the Chilean upwelling ecosystems as well as riverine input into the coastal zone (Strub et al. 1998, Davila et al. 2002, Böning et al. 2009). These elements may be transferred directly to the statolith from surrounding waters (Walther \& Thorrold 2006, Thorrold et al. 2007), or indirectly through maternal effects (Lloyd et al. 2008). Elemental signatures can also be affected by environmental variables such as temperature, diet, and salinity, and by endogenous factors such as growth rates and the type of $\mathrm{CaCO}_{3}$ crystal present within the otoliths (Gallahar \& Kingsford 1996, BathMartin et al. 2004, Bath-Martin \& Thorrold 2005, Ruttenberg et al. 2005, Zumholz et al. 2006). Therefore, we cannot conclude that the availability and concentration of chemical elements in the seawater are the only factors responsible for the differences in the elemental composition of statoliths. Future studies are needed to investigate the main factors that might influence the chemistry of statoliths of Concholepas concholepas. Because we sampled both pre-pelagic larvae and post-settlement recruits within the same time frame (separated by an appropriate pelagic larval duration), it is not necessary to specify the processes that might lead to regional differences in elemental signatures, nor is it necessary to verify temporal stability in those regional differences. The empirical demonstration of geographic variation in the natal signatures themselves allows for an analysis of long-distance dispersal.

In order to maximize the use of our resources, our study employed a combination of regional-scale collections with sparse local or fine-scale sampling. Our findings on the regional scale are corroborated by a previous study of Concholepas concholepas (Zacherl et al. 2003b) that indicated larval microchemistry can be a useful tool for identifying the natal sources in this species. However, because of gaps in the sampling scheme, we were not able to define the exact natal origin of the recruits. While we have strong indications of a lack of dispersal among regions, we cannot at this point infer the potential patterns of population connectivity or the magnitude of population interchange along the entire coast of Chile. Such an undertaking would entail much finer scale sampling, and, as mentioned above, many of these populations are severely depleted. The lack of dispersal among regions in C. concholepas is not in agreement with studies suggesting genetic homogeneity and a high level of gene flow in this species (Cárdenas et al. 2009). However, a small but significant genetic structure among populations of geographically separated populations of $C$. concholepas has also been reported by genetic studies with microsatellite markers (Cárdenas 2007). Therefore, future joint studies of elemental fingerprints and microsatellite markers will be needed to better understand the magnitude of dispersion in this species.

Techniques in otolith/statolith chemistry may be useful in addressing questions of larval connectivity if there is spatial variation in core chemistry resulting from differences in the environmental conditions at potential source areas. We detected elemental signatures in both the larval statolith of near-hatch larvae and recruit statolith natal cores of Concholepas concholepas, and found that elemental signatures of natal cores of near-hatch larvae allow discrimination among regions. This is in agreement with previous studies exhibiting spatial discrimination based on chemical signatures of statoliths of near-hatch larvae (Zacherl et al. 2003b, Warner et al. 2009). However, the combined and single elemental compositions of 
statolith cores in recruits of $C$. concholepas were different from the chemical signatures of natal cores of near-hatch larvae; both show regional discrimination, but the patterns of elemental differences were not the same. As a consequence, the recruit core signatures do not exhibit a strong overlap with the discriminatory space depicted by the chemical data of natal cores of near-hatch larvae (Fig. 5). Past studies of elemental fingerprints of pre-dispersal and postdispersal stages (see Warner et al. 2009) found that larvae and recruit cores generally lay in the same DFA space, raising the confidence in assignment. Given the differences in elemental signatures among recruits from the 3 geographical regions along the Chilean coast, and since both pre-release larvae and recruit cores of $C$. concholepas showed significant discrimination on a regional basis, we suggest that it is likely that there is little population interchange at the regional scale.

To address the question of larval connectivity in Concholepas concholepas at finer spatial scales, we must resolve the problems of small and geographically sparse sample sizes, as mentioned above. However, in research currently under way, we have designed and implemented a methodology that allows laboratory cultures with known origin egg capsules of C. concholepas containing early embryonic stages (i.e. without statoliths) and produced by known females (to control for the maternal effect) to be transplanted to different geographical areas where egg capsules are absent. A similar laboratory-field approach of in situ larval culturing has been successfully applied to investigate the temporal and spatial scales of variability in bivalve connectivity (Becker et al. 2005, Thorrold et al. 2007). C. concholepas has the advantage that one single female reared in the laboratory is able to spawn 100 s of egg capsules, making it possible to incorporate and control for maternal effects in the design of the study of natal elemental signatures.

Acknowledgements. The present study was supported by the project Fondecyt 1080023 to P.H.M., N.A.L., and J.C.C., and by the Partnership for the Interdisciplinary Study of Coastal Oceans (PISCO, with funding from the Packard Foundation and the Moore Foundation) to R.R.W. We thank M.E. Jara and F. Orellana for assistance in the laboratory and in the field. We also thank M. Oliva, J. Riascos, and A. Pacheco for kindly providing free laboratory and accommodation facilities in the 'Climate Variability and El Niño Southern Oscillation: Implications for Natural Coastal Resources and Management (CENSOR)' facility at the University of Antofagasta, Chile. We thank S. Navarrete, Director of the Estación Costera de Investigaciones Marinas (ECIM) at Las Cruces, for providing laboratory facilities at ECIM. Much appreciation goes to M. Lee for improving the
English of this manuscript. A portion of this study is part of the work conducted by S.G. to obtain her degree in Marine Biology at the Universidad Austral de Chile. We thank 3 anonymous reviewers for their valuable comments and for suggestions that greatly improved the manuscript. During the preparation of this manuscript P.H.M. and N.A.L. were funded by projects Fondecyt 1090624, ANILLOS ACT 132, and Project N000012742-UST to N.A.L. Editing and publication costs of this manuscript were covered by the Dirección de Investigación y Desarrollo de la Universidad Austral de Chile. This is PISCO Publication Number 142.

\section{LITERATURE CITED}

Bakker DCE, de Baar HJW, de Wilde HPJ (1996) Dissolved carbon dioxide in Dutch coastal waters. Mar Chem 55: 247-263

Bath-Martin G, Thorrold SR (2005) Temperature and salinity effects on magnesium, manganese, and barium incorporation in otoliths of larval and early juvenile spot Leiostomus xanthurus. Mar Ecol Prog Ser 293:223-232

> Bath-Martin G, Thorrold SR, Jones CM (2004) Temperature and salinity effects on strontium incorporation in otoliths of larval spot (Leiostomus xanthurus). Can J Fish Aquat Sci 61:34-42

Becker BJ, Fodrie FJ, McMillan PA, Levin LA (2005) Spatial and temporal variation in trace elemental fingerprints of mytilid mussel shells: a precursor to invertebrate larval tracking. Limnol Oceanogr 50:48-61

Böning P, Brumsack HJ, Schnetger B, Grunwald M (2009) Trace element signatures of Chilean upwelling sediments at $\sim 36^{\circ} \mathrm{S}$. Mar Geol 259:112-121

Cárdenas L (2007) Historia de expansión, efectos de eventos históricos y contemporaneos en el rango actual de distribución geográfica de Concholpeas concholepas: inferencias desde su estructura genética. PhD thesis, Pontificia Universidad Católica de Chile, Santiago

Cárdenas L, Castilla JC, Viard F (2009) A phylogeographical analysis across three biogeographical provinces of the south-eastern Pacific: the case of the marine gastropod Concholepas concholepas. J Biogeogr 36:969-981

> Carson HS (2010) Population connectivity of the Olympia oyster in southern California. Limnol Oceanogr 55:134-148

> Castilla JC, Defeo O (2001) Latin American benthic shellfisheries: emphasis on co-management and experimental practices. Rev Fish Biol Fish 11:1-30

> Castilla JC, Durán LR (1985) Human exclusion from the rocky intertidal zone of Central Chile: the effects on Concholepas concholepas (Gastropoda). Oikos 45:391-399

Castilla JC, Lagos N, Guiñez R, Largier J (2002) Embayments and nearshore retention of plankton: the Antofagasta Bay and other examples. In: Castilla JC, Largier J (eds) The Oceanography and ecology of the nearshore and bays in Chile. International symposium on linkages and dynamics of coastal systems: open coasts and embayments. Ediciones Universidad Católica de Chile, Santiago, p 179-203

Chittaro PM, Klinger T, Telmer K, Sanborn M, Morgan L (2010) Using otolith chemistry to investigate population structure of quillback rockfish in Puget Sound. Northwest Sci 84:243-254

> Cook GS (2011) Changes in otolith microchemistry over a protracted spawning season influence assignment of natal origin. Mar Ecol Prog Ser 423:197-209 
Dávila P, Figueroa D, Müller E (2002) Freshwater input into the coastal ocean and its relation with the salinity distribution off austral Chile $\left(35-55^{\circ} \mathrm{S}\right)$. Cont Shelf Res 22: 521-534

DiSalvo LH (1988) Observations of the larval and postmetamorphic life of Concholepas concholepas (Bruguière, 1789) in laboratory culture. Veliger 30:358-368

> Doubleday ZA, Pecl GT, Semmens JM, Danyushevsky L (2008) Stylet elemental signatures indicate population structure in a holobenthic octopus species, Octopus pallidus. Mar Ecol Prog Ser 371:1-10

Gallahar NK, Kingsford MJ (1996) Factors influencing Sr/Ca ratios in otoliths of Girella elevata: an experimental investigation. J Fish Biol 48:174-186

Gallardo C (1973) Desarrollo intracapsular de Concholepas concholepas (Bruguière) (Gastropoda, Muricidae). Publicaciones ocasionales No. 16, Museo de Historia Natural, Santiago de Chile

Gallardo MH, Carrasco JI (1996) Genetic cohesiveness among populations of Concholepas concholepas (Gastropoda, Muricidae) in southern Chile. J Exp Mar Biol Ecol 197:237-249

- Halpern BS, Warner RR (2003) Matching marine reserve design to reserve objectives. Proc Biol Sci 270:1871-1878

> Hand CP, Ludsin SA, Fryer BJ, Marsden JE (2008) Statolith microchemistry as a technique for discriminating among Great Lake sea lamprey (Petromyzon marinus) spawning tributaries. Can J Fish Aquat Sci 65:1153-1164

Kinlan BP, Gaines SD (2003) Propagule dispersal in marine and terrestrial environments: a community perspective. Ecology 84:2007-2020

Koch SE (2008) Exploring the use of statoliths of Kelletia kelletii as natural tags to estimate population connectivity across a species' range. $\mathrm{PhD}$ dissertation. California State University, Fullerton, CA

> Lagos NA, Navarrete SA, Véliz F, Masuero A, Castilla JC (2005) Meso-scale spatial variation in settlement and recruitment of intertidal barnacles along the coast of central Chile. Mar Ecol Prog Ser 290:165-178

> Lagos NA, Castilla JC, Broitman BR (2008) Spatial environmental correlates of intertidal recruitment: a test using barnacles in northern Chile. Ecol Monogr 78:245-261

> Leiva G, Castilla JC (2002) A review of the world gastropod fishery: evolution of catches, management and the Chilean experience. Rev Fish Biol Fish 11:283-300

> Lloyd DC, Zacherl DC, Walker S, Paradis G, Sheehy M, Warner RR (2008) Egg source, temperature and culture seawater affect elemental signatures in Kelletia kelletii larval statoliths. Mar Ecol Prog Ser 353:115-130

> Manríquez PH, Castilla JC (2001) Significance of marine protected areas in central Chile as seeding grounds for the gastropod Concholepas concholepas. Mar Ecol Prog Ser 215:201-211

Manríquez PH, Castilla JC (2011) Behavioral traits of competent Concholepas concholepas (loco) larvae. Mar Ecol Prog Ser 430:207-221

Manríquez PH, Navarrete S, Rosson A, Castilla JC (2004) Settlement of the gastropod Concholepas concholepas on shells of conspecific adults. J Mar Biol Assoc UK 84: 651-658

> Manríquez PH, Delgado AP, Jara ME, Castilla JC (2008) Field and laboratory experiments with early ontogenetic stages of Concholepas concholepas. Aquaculture 279: 99-107

Manríquez PH, Lagos NA, Jara ME, Castilla JC (2009)
Adaptive shell color plasticity during the early ontogeny of an intertidal keystone snail. Proc Natl Acad Sci USA 106:16298-16303

> Martínez P, Navarrete SA (2002) Temporal and spatial variation in settlement of the gastropod Concholepas concholepas in natural and artificial substrata. J Mar Biol Assoc U K 82:257-264

Miller A (1976) The climate of Chile. In: Schwerdtfeger E (ed) World survey of climatology. Elsevier, Amsterdam, p 113-145

Moreno CA, Sutherland JP, Jara HF (1984) Man as a predator in the intertidal zone of southern Chile. Oikos 42: $155-160$

Palumbi SR (2002) Marine reserves: a tool for ecosystem management and conservation. Pew Ocean Commission Reports, Pew Ocean Commission, Arlington, VA

> Planes S, Jones GP, Thorrold SR (2009) Larval dispersal connects fish populations in a network of marine protected areas. Proc Natl Acad Sci USA 106:5693-5697

> Poulin E, Palma AT, Leiva G, Hernández E, Martínez P, Navarrete SA, Castilla JC (2002) Temporal and spatial variation in the distribution of epineustonic competent larvae of Concholepas concholepas along the central coast of Chile. Mar Ecol Prog Ser 229:95-104

> Ruttenberg BI, Warner RR (2006) Spatial variations in the chemical composition of natal otoliths from a reef fish in the Galápagos Islands. Mar Ecol Prog Ser 328:225-236

> Ruttenberg BI, Hamilton SL, Hickford MJH, Paradis GL and others (2005) Elevated levels of trace elements in cores of otoliths and their potential use as natural tags. Mar Ecol Prog Ser 297:273-281

Ruttenberg BI, Hamilton SL, Warner RR (2008) Spatial and temporal variations in the natal otolith chemistry of a Hawaiian reef fish: prospects for measuring population connectivity. Can J Fish Aquat Sci 65:1181-1192

Strub T, Mesias J, Montecinos V, Rutland J, Salinas S (1998) Coastal ocean circulation off western South America. In: Robinson AR, Brink KH (eds) The sea, vol. 11. Wiley, New York, p 273-313

> Swearer SE, Caselle JE, Lea DW, Warner RR (1999) Larval retention and recruitment in an island population of a coral-reef fish. Nature 402:799-802

- Takesue RK, van Geen A (2004) Mg/Ca, Sr/Ca, and stable isotopes in modern and Holocene Protothaca staminea shells from a northern California coastal upwelling region. Geochim Cosmochim Acta 68:3845-3861

> Ternon JF, Oudot C, Dessier A, Diverres D (2000) A seasonal tropical sink for atmospheric $\mathrm{CO}_{2}$ in the Atlantic Ocean: the role of the Amazon River discharge. Mar Chem 68: 183-201

> Thorrold SR, Jones CM, Swart PK, Targett TE (1998) Accurate classification of juvenile weakfish Cynoscion regalis to estuarine nursery areas based on chemical signatures in otolith. Mar Ecol Prog Ser 173:253-265

Thorrold SR, Jones GP, Hellberg ME, Burton ME and others (2002) Quantifying larval retention and connectivity in marine populations with artificial and natural markers: Can we do it right? Bull Mar Sci 70:291-308

Thorrold SR, Zacherl DC, Levin LA (2007) Quantifying population connectivity via larval dispersal using geochemical signatures in calcified structures. Oceanography (Wash DC) 20:80-89

> Walther BD, Thorrold SR (2006) Water, not food, contributes the majority of strontium and barium deposited in the otoliths of a marine fish. Mar Ecol Prog Ser 311:125-130 
Warner RR, Swearer SE, Caselle JE, Sheehy MS, Paradis GL (2005) Natal trace-elemental signatures in the otoliths of an open-coast fish. Limnol Oceanogr 50: 1529-1542

Warner RR, Hamilton SL, Sheehy MS, Zeidberg LD, Brady $\mathrm{BC}$, Caselle JE (2009) Geographic variation in natal and early larval trace-elemental signatures in statoliths of the market squid Doryteuthis (formerly Loligo) opalescens. Mar Ecol Prog Ser 379:109-121

> White JW, Ruttenberg BI (2007) Discriminant function analysis in marine ecology: some oversights and their solutions. Mar Ecol Prog Ser 329:301-305

Zacherl DC (2005) Spatial and temporal variation in statolith and protoconch trace elements as natural tags to track larval dispersal. Mar Ecol Prog Ser 290:145-163

Editorial responsibility: Ivan Nagelkerken, Nijmegen, Netherlands
Zacherl DC, Paradis G, Lea DW (2003a) Barium and strontium uptake into larval protoconchs and statoliths of the marine neogastropod Kelletia kelletii. Geochim Cosmochim Acta 67:4091-4099

Zacherl DC, Manríquez PH, Paradis G, Day RW and others (2003b) Trace elemental fingerprinting of gastropod statoliths to study larval dispersal trajectories. Mar Ecol Prog Ser 248:297-303

> Zumholz K, Hansteen TH, Klügel A, Piatkowski U (2006) Food effects on statolith composition of the common cuttlefish (Sepia officinalis). Mar Biol 150:237-244

> Zumholz K, Hansteen TH, Klügel A, Croot PL (2007) Influence of temperature and salinity on the trace element incorporation into statoliths of the common cuttlefish (Sepia officinalis). Mar Biol 151:1321-1330

Submitted: May 23, 2011; Accepted: November 18, 2011 Proofs received from author(s): 14 February, 2012 